\title{
A FEIRA DE PRODUTOS EM TRANSIÇÃO AGROECOLÓGICA DO IFMS CORUMBÁ
}

\author{
IFMS Corumbá Agroecological Transition Fair
}

Feria de Transición Agroecológica de IFMS Corumbá

\author{
Mariane Letícia Leite da Cruz Costa* \\ Edgar Aparecido da Costa**
}

* Licenciada em Geografia, Mestranda em Estudos Fronteiriços, UFMS. Técnica administrativa do IFMS Campus Corumbá - marianeleticia@yahoo.com.br

** Doutor em Geografia, professor do curso de Geografia e do Programa de Pós-Graduação em Estudos Fronteiriços do Câmpus Pantanal, UFMS - edgarac10@gmail.com

Recebido em 16/03/2020. Aceito para publicação em 17/03/2020.

Versão online publicada em 05/05/2020 (http://seer.ufrgs.br/paraonde)

\begin{abstract}
Resumo:
O tema norteador deste trabalho é a agroecologia no espaço fronteiriço. O objetivo foi realizar um levantamento das percepções que os técnicos administrativos do IFMS Campus Corumbá têm sobre a feira de agroecologia que acontece no espaço institucional. Para tanto, buscou-se reunir considerações sobre fronteira, através de pesquisa bibliográfica. Realizou-se, também, levantamento de dados primários tendo um questionário como instrumento, que foi aplicado aos técnicos presentes na instituição, sendo respondido por 20 pessoas. Observou-se o interesse em adquirir produtos agroecológicos como forma de se obter uma alimentação de mais qualidade.
\end{abstract}

Palavras-chave: Agroecologia. IFMS. Fronteira.

\begin{abstract}
:
The guiding theme of this work is agroecology in the border space. The objective was to survey the perceptions that the administrative technicians of IFMS Campus Corumbá have about the agroecology fair that takes place in the institutional space. To this end, we sought to gather border considerations through bibliographic research. A primary data survey was also carried out with a questionnaire as an instrument, which was applied to the technicians present at the institution, being answered by 20 people. The interest in acquiring agroecological products was observed as a way to obtain a higher quality diet.
\end{abstract}

Key-words: Agroecology. IFMS. Border.

\section{Resumen:}

El tema principal de este trabajo es la agroecología en el espacio fronterizo. El objetivo fue realizar una encuesta sobre las percepciones que los técnicos administrativos de IFMS Campus Corumbá tienen sobre la feria de agroecología que se lleva a cabo en el espacio institucional. Con este fin, buscamos reunir consideraciones fronterizas a través de la investigación bibliográfica. También se realizó una encuesta de datos primarios con un cuestionario como instrumento, que se aplicó a los técnicos presentes en la institución, respondiendo 20 personas. Se observó el interés en adquirir productos agroecológicos como una forma de obtener una dieta de mayor calidad.

Palabras-clave: Agroecología. IFMS. Frontera. 


\section{Introdução}

A cidade de Corumbá-MS é complexa no que se refere à população. Ao mesmo tempo em que abriga seus habitantes, também recebe, temporariamente, pessoas das áreas vizinhas para estudar, trabalhar, utilizar seus serviços ou para lazer. Os vizinhos em questão são moradores das cidades de Ladário/MS (Brasil), além de Puerto Quijarro e Puerto Suárez (Santa Cruz, Bolívia) que compõem a fronteira em estudo.

Em Corumbá, a convivência entre brasileiros e bolivianos já faz parte do cotidiano. Uma das manifestações que mais evidencia essa convivência é a regularidade das feiras livres que acontecem nas cidades brasileiras da fronteira estudada. As feiras, como são popularmente conhecidas, acontecem diariamente, em localidades especificadas em Lei Municipal. Constitui um evento tradicional para muitas donas de casa e famílias e chamam a atenção pelos baixos preços praticados pelos feirantes (ESPÍRITO SANTO, COSTA e BENEDETTI, 2017).

Os feirantes, em sua maioria, são de nacionalidade boliviana e costumam comercializar variados tipos de mercadorias (ESPÍRITO SANTO, COSTA e BENEDETTI, 2017). Destaca-se o comércio de hortaliças trazidos por eles, constituindo fonte de produtos mais frescos.

A agroecologia tem sido uma das formas de produção barata e sustentável, capaz de promover diferencial frente ao comércio geral de hortaliças pois baseia-se no cultivo com redução de pesticidas e agroquímicos, tornando os produtos mais saudáveis para o consumo humano (SANTOS, 2014).

O Instituto Federal de Educação, Ciência e Tecnologia do Mato Grosso do Sul (IFMS) é uma instituição que tem a preocupação com a qualidade vida de seus servidores, e por meios de ações de extensão continuamente promove atividades que busquem estimular hábitos saudáveis, inclusive a busca por uma alimentação melhor. Uma das iniciativas foi a extensão da Feira de Transição Agroecológica no Campus Corumbá a partir do Núcleo de Estudos em Agroecologia e Produção Orgânica do Pantanal (NEAP), estabelecendo uma alternativa para a comunidade da instituição em adquirir produtos agroecológicos como forma de subsidiar uma dieta composta de produtos naturais e livres de agroquímicos.

O objetivo deste trabalho foi discutir as percepções dos servidores técnicos do IFMS Corumbá sobre a feira de produtos em transição agroecológica. Para tanto, utilizou-se de conversa informal com a idealizadora da feira no IFMS e aplicou-se um questionário a com intuito a abordar todos os técnicos administrativos lotados no Campus Corumbá.

$\mathrm{O}$ artigo foi organizado em três itens. O primeiro item procura apontar 0 entendimento que se faz sobre fronteira e das implicações para a comércio entre as localidades. Em seguida busca-se discutir o conceito de agroecologia e descrever a formação da feira do IFMS. Finalmente, apresenta-se a percepção dos servidores técnicos do IFMS sobre a feira na Instituição.

ParaOnde!?, Porto Alegre, v.13, n.2, p.16-27, 2020.http://seer.ufrgs.br/paraonde Edição Especial - VII Seminário Internacional de Estudos Fronteriços 


\section{Breve noção de fronteira e as implicações da localização territorial nessas áreas}

A área determinada para este estudo encontra-se num espaço fronteiriço, ou simplesmente fronteira. Por ser um local de encontros a fronteira acomoda manifestações diferenciadas. A heterogeneidade dos povos que a compõem pode gerar certos conflitos, todavia o enriquecimento da cultura acontece quase que naturalmente.

Sobre as interações que ocorrem em uma fronteira, Rodrigues (2015, p. 140) chama a atenção para o seguinte:

[...] não se pode deixar de observar que a fronteira não é mais considerada somente um limite físico ou político, desprovido de sujeitos e relações, da mesma forma que o território não é mais compreendido somente como uma demarcação espacial, dotado de características físicas e sociais. As práticas sociais, as relações, as ações políticas (Estado) e as redes passam a ser fundamentais na interpretação contemporânea de fronteira e território.

Ao apontar na fronteira como um espaço com identidade própria, Nogueira (2007, p. 29) sintetiza o pensamento de Ratzel ao tratar a fronteira "como o invólucro do Estado-nacional dentro do qual a mesmo se desenvolveria [...] e que ela retrata apenas um momento do desenvolvimento do Estado, podendo ser alterada no decurso do tempo, sendo, portanto, móvel".

A natureza de uma fronteira passa ser interpretada também pelas suas peculiaridades. Certas características inerentes às regiões de fronteiras são fundamentais para entender o mecanismo de vivência dos sujeitos que nelas habitam. Voltando a Nogueira (2007, p. 32), "pensar a fronteira como centro implica, inicialmente, numa mudança metodológica, em que a fronteira deva ser compreendida como um lugar de moradia e de existência de seus habitantes".

O ser humano tem a característica de se comunicar como um meio social, uma manifestação capaz de aproximar povos e lugares. Vive-se uma tendência mundial de aproximação, fortalecida até mesmo pela evolução científica. Conforme Machado (1998, p. 41):

[...] a palavra fronteira nasceu como um fenômeno da vida social espontânea, indicando a margem do mundo habitado. Na medida que os padrões de civilização foram se desenvolvendo acima do nível de subsistência, as fronteiras entre ecúmenos tornaram-se lugares de comunicação.

Grimson (2000, p. 3) esclarece que "las fronteras son espacios de condensación de procesos socioculturales. Esas interfases tangibles de los Estados nacionales unen y separan de modos diversos, tanto en términos materiales como simbólicos". No entanto, a própria combinação sociocultural constitui fator determinante na construção da identidade do espaço fronteiriço.

Para Steiman e Machado (2002), o trabalho é um fator de aproximação entre os povos, produzindo efeitos nas comunidades de ambos os lados da fronteira. A diferença de desenvolvimento entre dois países que dividem um espaço fronteiriço pode ser um atrativo para as pessoas que habitam o outro. Segundo as autoras:

ParaOnde!?, Porto Alegre, v.13, n.2, p.16-27, 2020.http://seer.ufrgs.br/paraonde Edição Especial - VII Seminário Internacional de Estudos Fronteriços 
As oportunidades que oferece um Estado mais desenvolvido, sobretudo para a realização de tarefas pesadas descartadas pelos profissionais qualificados desse mesmo Estado, acarretam ao longo do tempo grande fluxo de trabalhadores do lado pobre para o lado mais rico do limite internacional (STEIMAN e MACHADO, 2002, p.12).

Por tudo que já foi exposto entende-se que espaços fronteiriços estão sujeitos às manifestações que atendam sua forma fronteiriça, até mesmo com relação ao trabalho, seja urbano ou rural.

A área escolhida para estudo é o IFMS Campus de Corumbá, que acolhe em suas dependências a Feira de Transição Agroecológica. O Campus está localizado em um bairro próximo ao Centro, o que facilita a integração com outros pontos da cidade. Essa característica proporciona um grande alcance por pessoas de várias localidades, inclusive de cidades vizinhas.

\section{Conceito de agroecologia e a feira de produtos em transição agroecológica do IFMS Corumbá}

A agroecologia, conforme Canuto (2017, p. 139), "é praticada historicamente desde o nascimento da agricultura no período Neolítico. Sua concepção conceitual, no entanto, pode ser temporalmente localizada no final do Século XIX e, principalmente, no início do século XX". Em sequência, Canuto (2017, p. 140) cita Fukuoka, pioneiro no estudo sobre a agroecologia, que entendeu a ciência como uma nova prática no manejo do solo além de preservar a composição vegetal através de técnicas e auxílio da própria natureza.

Caporal (2004, p. 8) afirma que a agroecologia, "surge como um novo enfoque científico, capaz de dar suporte a uma transição a estilos de agriculturas sustentáveis e, portanto, contribuir para o estabelecimento de processos de desenvolvimento rural sustentável". Pensando no uso do solo, Sevilla-Guzmán (2006, p. 10) reflete que "la degradación del suelo (erosión hídrica y eólica, salinización y sodización, degradación química, física y biológica) es una de las mayores amenazas para la sostenibilidad de la agricultura".

A sustentabilidade que está na base de pensar e fazer da agroecologia traz benefícios à terra, mas também aos envolvidos com ela. Para o agricultor, afastando-o do contato exaustivo com agentes químicos de natureza tóxica ou para quem recebe os produtos em transição agroecológica, recebedores finais de um alimento verdadeiramente saudável (CAPORAL, 2004). Complementando o sentido de preocupação social da agroecologia, Sevilla-Guzmán (2006, p.14) explica que:

La Agroecología utiliza un enfoque integral en la que las variables sociales ocupan un papel muy relevante ya que aunque parta de la dimensión técnica (artificialización ecocompatible de la naturaleza para obtener alimentos) y su primer nivel de análisis sea la finca; desde ella, se pretende entender las múltiples formas de dependencia que el funcionamiento actual de la política, la economía y la sociedad genera sobre los agricultores.

Contudo, o conceito de agroecologia vai além de medidas direcionadas à agricultores ou simples manejo de terra, a fundamentação tem alcance de

ParaOnde!?, Porto Alegre, v.13, n.2, p.16-27, 2020.http://seer.ufrgs.br/paraonde Edição Especial - VII Seminário Internacional de Estudos Fronteriços 
proporções mundiais que colabore para o futuro da alimentação. Mas na produção de alimentos saudáveis reside a preocupação por traz da sua prática. Conforme Caporal (2004, p. 16), "a agroecologia tem como um de seus eixos centrais a necessidade de produção de alimentos em quantidades adequadas e de elevada qualidade biológica, para toda a sociedade".

Stoppelli e Magalhães (2005) sugerem a busca por alimentos mais saudáveis e com menos concentração de agrotóxicos e pesticidas é impulsionada por gerações que estão cada vez mais preocupadas com a saúde. Atrelada a essa preocupação estão as incertezas da qualidade dos produtos industrializados. Nascimento et al. (2019, p. 294) enfatizam:

\section{[...] as incertezas sobre a eficiência e a qualidade dos grandes sistemas agroalimentares ganham mais forças com o aumento de notícias sobre crises alimentares que afetam diversos setores da produção agrícola e se tornam amplamente conhecidos, como a crise da vaca louca, intoxicação por dioxinas, gripes aviárias e suínas entre outros.}

Com a agroecologia tem-se a possibilidade de propor o trabalho com a terra pela cooperação entre os agricultores. Essa perspectiva vem ao encontro da realidade da cidade de Corumbá, onde agroecologia já vem sendo trabalhada como novo experimento para que os agricultores locais possam se desenvolver.

A cidade de Corumbá foi uma das localidades escolhidas para implantação de um dos dez campi do IFMS. Os Institutos Federais são autarquias que foram instituídas no âmbito do sistema federal de ensino, a Rede Federal de Educação Profissional, Científica e Tecnológica, vinculada ao Ministério da Educação e constituída inicialmente por 38 instituições pelo Brasil. No Mato Grosso do Sul o Instituto Federal foi criado, pela lei 11.892/2008, em integração à Escola Técnica Federal de Mato Grosso do Sul e da Escola Agrotécnica Federal de Nova Andradina (BRASIL, 2008). A fase de transição e consolidação do IFMS Campus Corumbá não é rápida nem simplificada. De modo geral todos os novos procedimentos são estudados e avaliados pela equipe de gestão do campus em conjunto com a reitoria antes de serem implementados para a comunidade de alunos, pais e servidores.

O IFMS é uma instituição que vislumbra a qualidade de vida de seus servidores. Cada campus de atuação no estado possui um segmento chamado de Comissão de Qualidade de Vida, e tem por objetivo auxiliar seus colaboradores na busca de uma vida mais saudável, seja pelo incentivo a prática de exercícios físicos regulares, seja pela conscientização da alimentação adequada.

No Campus Corumbá a equipe de técnicos administrativos atual é composta por 45 servidores, dentre eles uma psicóloga organizacional, idealizadora da implantação da Feira de Transição Agroecológica no Campus Corumbá. Conhecida a atuação da feira que já ocorria em outros órgãos como Embrapa Pantanal e UFMS na cidade de Corumbá, apoiados pelo projeto do NEAP - Núcleo de Estudos em Agroecologia e Produção Orgânica do Pantanal, 0 interesse em trazer para o IFMS foi iminente.

A Embrapa Pantanal e a UFMS desenvolvem atividades no segmento da agroecologia desde $\mathrm{o}$ ano de 2011. Os primeiros projetos de pesquisa e

ParaOnde!?, Porto Alegre, v.13, n.2, p.16-27, 2020.http://seer.ufrgs.br/paraonde Edição Especial - VII Seminário Internacional de Estudos Fronteriços 
extensão visavam a melhoria na qualidade de vida dos agricultores do assentamento 72, apostando no desenvolvimento rural sustentável de acordo com da Política Nacional de Assistência Técnica e Extensão Rural para a Agricultura Familiar e Reforma Agrária (PNATER). A partir dos resultados dos projetos criou-se a Feira de Produtos em Transição Agroecológica no Câmpus do Pantanal (CPAN) da Universidade Federal de Mato Grosso do Sul (UFMS), que mais tarde ampliara-se para a Embrapa e IFMS.

No ano de 2018, durante a Semana do Meio Ambiente que ocorre anualmente no mês de junho, o Campus Corumbá trouxe para suas dependências a Feira Agroecológica (Figura 1). A parceria surgiu em conjunto com o projeto já realizado pelo Campus do Pantanal da UFMS e o NEAP, onde agricultores do Assentamento 72 trouxeram produtos frescos para venda, visando o incentivo ao consumo de alimentos naturais mais saudáveis além de outros produzidos por eles, como mel, queijos e doces. O Assentamento 72 fica localizado no município de Ladário, vizinho de Corumbá.

Figura 1 - Feira de Transição Agroecológica no IFMS Campus Corumbá.

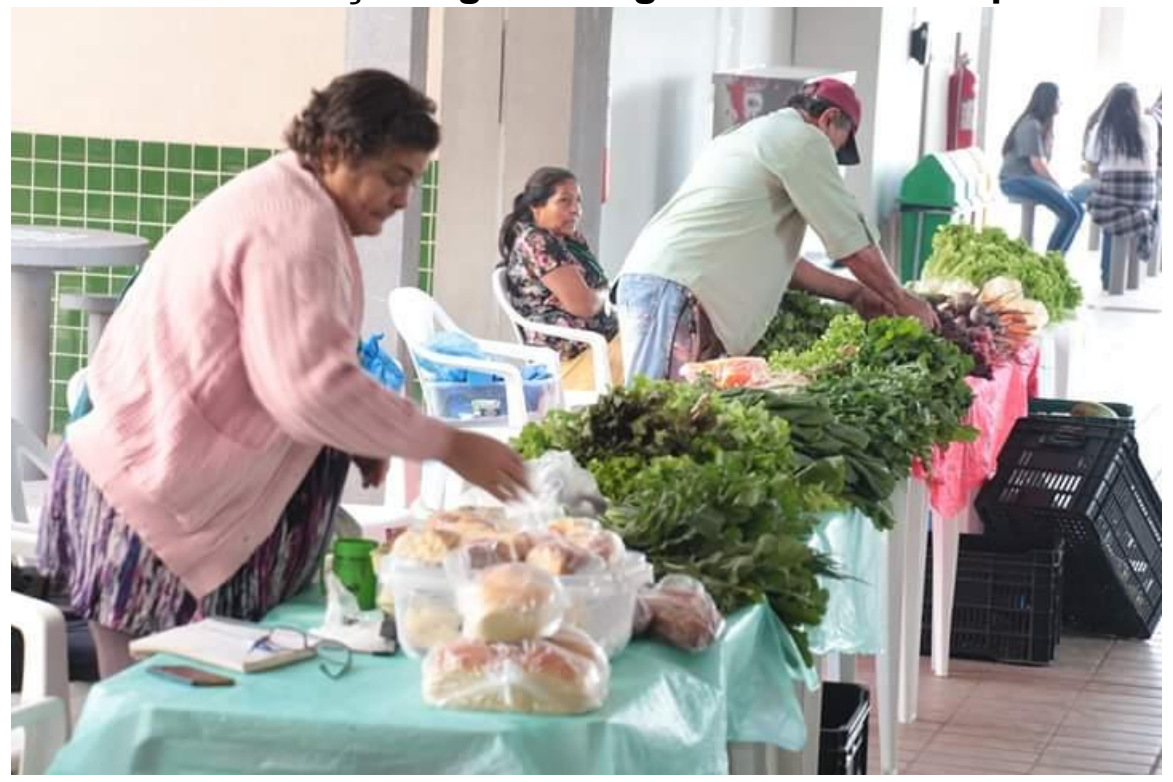

Fonte: Arquivo IFMS. Foto tirada em 15 de agosto de 2019.

Em agosto do mesmo ano a Feira Agroecológica passou a ser realizada semanalmente no IFMS, sempre às quintas-feiras no período da manhã. $A$ necessidade de apoiar pequenos agricultores locais é reforçada pelo intuito de direcionar as pessoas a refletirem sobre a segurança alimentar e nutricional.

A questão que se coloca nesta fronteira é a ausência de conhecimento da procedência dos alimentos que são oferecidos nos supermercados e nas feiras livres. Observa-se nas feiras, que apesar de a maioria dos comerciantes serem bolivianos a maior parte dos produtos agrícolas são de origem brasileira, adquiridos de assentamentos rurais de Corumbá e Ladário ou até mesmo da Central de Abastecimento de Mato Grosso do Sul (CEASA-MS) e da Companhia de Entrepostos e Armazéns Gerais de São Paulo (CEAGESP). Com relação aos

ParaOnde!?, Porto Alegre, v.13, n.2, p.16-27, 2020.http://seer.ufrgs.br/paraonde Edição Especial - VII Seminário Internacional de Estudos Fronteriços 
produtos que realmente são provenientes do excedente da agricultura familiar boliviana os feirantes não sabem dizer se são produzidos com agrotóxicos (ESPÍRITO SANTO, COSTA e BENEDETTI, 2017).

Todavia, o conceito de produtos em transição agroecológica já vem sendo trabalhado pelos agricultores de Corumbá. Costa et al. (2016, p. 3) descrevem:

Do assentamento 72 os feirantes são membros do Grupo de Agricultores Agroecológicos Bem-Estar. [...] O carro chefe da feira é o Grupo Bem-Estar, do assentamento 72, que desde 2011 vem experimentando formas de produção sem uso de venenos para hortaliças. Os princípios da agroecologia foram e ainda são insistentemente disseminados e incentivados pelos pesquisadores da Embrapa Pantanal e da UFMS.

O trabalho em conjunto das instituições oferece o ateste, através do NEAP, para a procedência dos produtos do Grupo Bem-Estar. Os projetos que originaram o Grupo Bem-Estar culminaram em Feiras de Produtos em Transição Agroecológica, a exemplo da que ocorre semanalmente no IFMS Campus Corumbá.

\section{Percepções dos técnicos do IFMS Corumbá sobre a feira do IFMS}

Nessa pesquisa buscou-se identificar as principais percepções dos técnicos-administrativos sobre a feira de transição agroecológica que acontece semanalmente dentro das instalações do Campus Corumbá. Para isso foi aplicado o questionário contendo 19 perguntas para identificação do perfil dos consumidores, seus conhecimentos sobre a feira e atratividade dos produtos agroecológicos. A aplicação ocorreu em 16 de agosto de 2019, dia seguinte a uma edição da feira.

A delimitação do público entrevistado justifica-se por serem os mais próximos das instalações da realização da feira dentro do espaço do IFMS. $O$ resultado desse estudo é fundamental para traçar estratégias para alcançar esse e outros públicos.

A intenção inicial de atingir a totalidade dos técnicos administrativos não foi alcançada. Dentre os 20 que responderam ao questionário notou-se que a maioria dos frequentadores da feira são do sexo feminino, cerca de $67 \%$. Esse resultado de certa forma indica a predisposição das mulheres para a alimentação saudável. Considerando que a entrevista foi realizada apenas com servidores do IFMS. Dantas et al. (2011), perceberam resultados semelhantes ao pesquisarem a aceitabilidade dos produtos orgânicos na feira agroecológica de Bananeiras/PB. Encontrarem $65 \%$ do sexo feminino, atribuindo esse resultado ao fato da mulher ser responsável pela aquisição da alimentação da família e consequentemente priorizar produtos mais saudáveis.

O nível de instrução e renda familiar mostrou-se elevado, sendo que $15 \%$ estão concluindo o ensino superior, $70 \%$ possuem nível de graduação ou especialização e $15 \%$ estão em nível de mestrado ou doutorado concluído. Observou-se que apenas 10\% recebem de 1 a 3 salários mínimos, 50\% entre 4 e 6 salários mínimos e $40 \%$ entre 7 e 11 salários mínimos. Ao buscar a caracterização do consumo em uma feira livre de base ecológica do Município

ParaOnde!?, Porto Alegre, v.13, n.2, p.16-27, 2020.http://seer.ufrgs.br/paraonde Edição Especial - VII Seminário Internacional de Estudos Fronteriços 
de Pelotas/RS Lovatto et al. (2009) observaram a predominância de consumidores com nível superior (69\%), seguidos de portadores do Ensino Médio (22\%).

Para determinado grupo de perguntas foi utilizado a escala de 1 a 5, onde 1 indica a menor importância e 5 a maior importância. Percebeu-se que 0 principal motivo da preferência em adquirir produtos comercializados na feira de transição agroecológica pelo público analisado é a qualidade do produto acompanhado ao fato de ter sido produzido sem agrotóxicos. Dos servidores que responderam ao questionário, 94\% atribuíram grau de muita importância ao consumo de produtos sem o uso de agroquímicos e $80 \%$ tiveram a mesma percepção na decisão pela compra de um determinado produto da feira. Os produtos apresentam aspectos de frescor e qualidade (Figuras 2 e 3), atraindo 0 interesse para consumo. Isso foi decisivo para a compra dos produtos em $87 \%$ dos entrevistados.

Figura 2 e 3 - Produtos comercializados na Feira de Transição Agroecológica no IFMS Campus Corumbá.

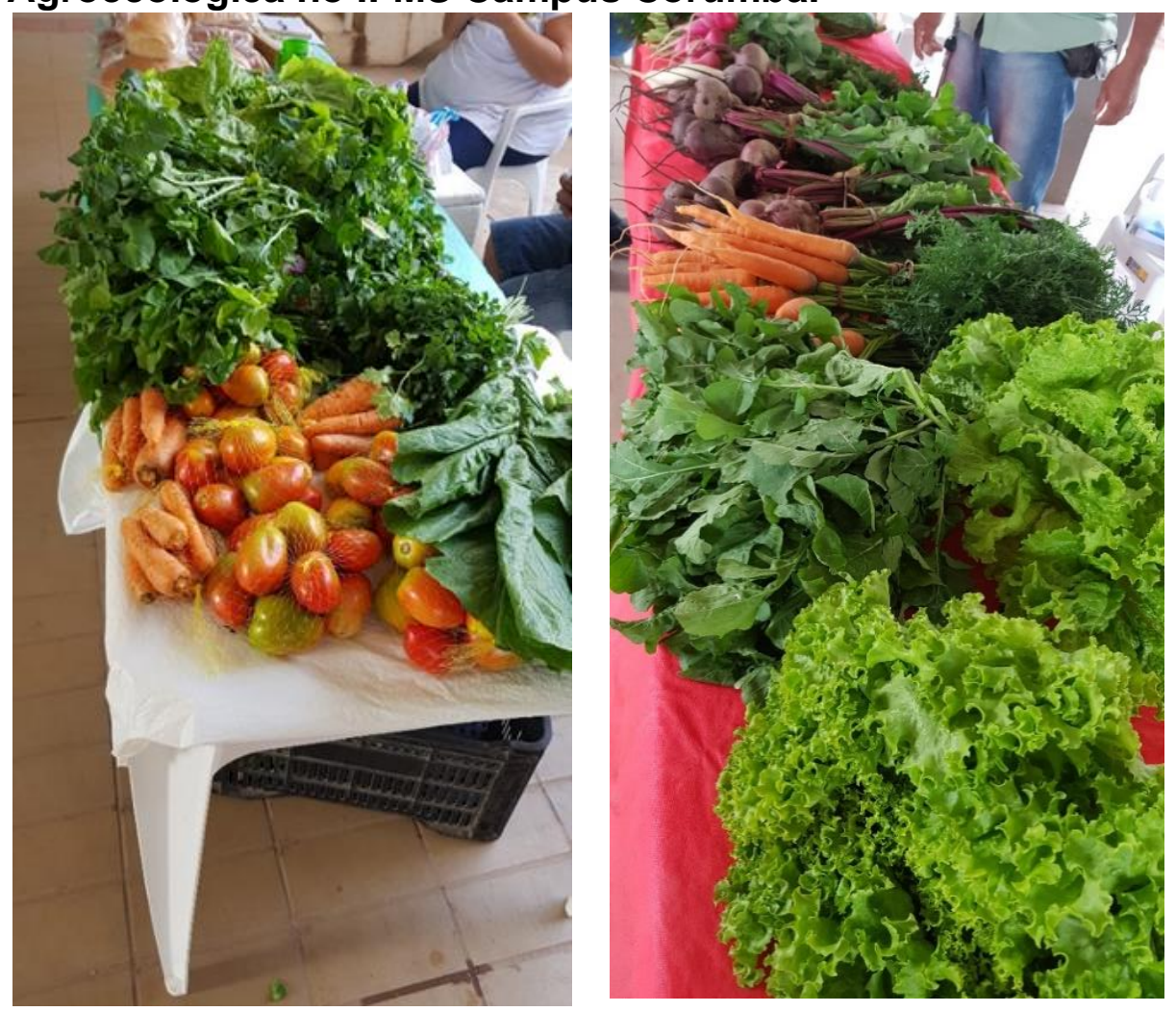

Fonte: Arquivo IFMS. Foto tirada em 08 de agosto de 2019.

A tendência de as pessoas estarem preocupadas com as crises que afetam a indústria da alimentação, apresentada por Nascimento et al. (2009, p. 294), também foi constatada nesta pesquisa, onde $100 \%$ dos entrevistados atribuíram grau de muita importância à qualidade de vida associada ao consumo de produtos agroecológicos. O mesmo resultado foi alcançado por Gonçalves et al. (2016), ao estudarem a percepção de consumidores sobre a feira do Parque Água Branca, na cidade de São Paulo-SP, quando $100 \%$ do pesquisados

ParaOnde!?, Porto Alegre, v.13, n.2, p.16-27, 2020.http://seer.ufrgs.br/paraonde Edição Especial - VII Seminário Internacional de Estudos Fronteriços 
concordaram que o consumo de alimentos orgânicos traz benefícios à saúde. De forma semelhante, Cruvinel et al. (2017) entrevistaram 87 consumidores de uma feira livre na cidade de Goiânia/GO e detectaram que 66,7\% atribuíram atenção à saúde na decisão da compra de alimentos orgânicos.

Quando se questionou há quanto tempo consumiam produtos derivados da agroecologia, observou-se que $50 \%$ dos consultados responderam que iniciaram o consumo a menos de 1 ano e $29 \%$ entre 1 a 2 anos (Figura 4). Lembrando que a feira começou a funcionar dentro do IFMS Campus Corumbá no ano de 2018, esse dado demonstra a influência da presença da feira em meio ao ambiente de trabalho, facilitando o acesso à produtos agroecológicos e possivelmente incorporando um novo modo de vida aos que passam a consumilos.

A pesquisa de Cruvinel et al. (2017) observou a mesma tendência no aumento de consumidores de alimentos orgânicos. Encontraram 28,6\% que seus entrevistados consomem produtos orgânicos a 1 ano ou menos, $19,0 \%$ a 2 anos e $23,8 \%$ a 3 anos.

\section{Figura 4 - Tempo de consumo de produtos agroecológicos.}

\section{A quanto tempo você consome produtos derivados da Agroecologia?}

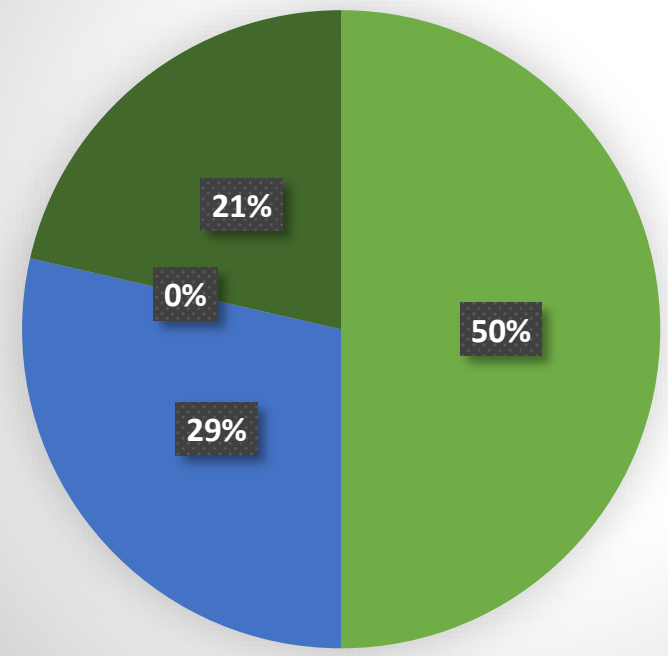

menos de 1 ano

a 1 a 2 anos

2 a 3 anos

mais de três anos

Fonte: Pesquisa de campo, 2019.

Com relação à frequência, os consumidores descreveram que adquirem os produtos, em sua maior parte, semanalmente ou quinzenalmente $(50 \%$ e $45 \%$ respectivamente). Constância que coincide com a regularidade da feira que é semanal. Os servidores entrevistados mostraram-se satisfeitos com a forma de comercialização dos produtos agroecológicos no IFMS, concentrando $79 \%$ de satisfeitos e $21 \%$ de não satisfeitos, que detalharam como única insatisfação a pouca variedade de produtos. Dentre os produtos que ainda não são ofertados, $40 \%$ dos entrevistados desejam que frutas também sejam trazidas.

Outro ponto importante a ser observado é a percepção que se tem sobre

ParaOnde!?, Porto Alegre, v.13, n.2, p.16-27, 2020.http://seer.ufrgs.br/paraonde Edição Especial - VII Seminário Internacional de Estudos Fronteriços 
a possibilidade de alcançar os jovens estudantes do IFMS com temas de alimentação saudável a partir de produtos agroecológicos. A presença da feira em um ambiente escolar foi considerada como importante aliado na construção de valores alimentares e sociais. Um dos entrevistados argumentou: "A feira agroecológica é um instrumento importantíssimo na educação alimentar e nutricional de um ambiente escolar. Contribui para a adoção de escolhas saudáveis e seguras, qualidade de vida e sobretudo, fomento da agricultura". Outro, utilizou as seguintes palavras para descrever o possível transbordamento positivo da feira: "É importante manter no ' $I F$ ', pois atua como educação ambiental e alimentar".

\section{Considerações finais}

A agroecologia é um tema que vem ganhando cada vez mais espaço no cotidiano das pessoas. A busca pela qualidade de vida, a dizer, na alimentação, torna-se cada vez mais importante. Os espaços fronteiriços são passíveis de fluidez e porosidade. No caso da fronteira estudada, os bolivianos comercializam grande variedade de hortaliças adquiridas de diversas localidades. A falta de conhecimento da procedência dos alimentos pode implicar numa alimentação com ingestão de resíduos de agroquímicos.

O IFMS acerta ao apostar na inclusão de uma feira exclusivamente de produtos agroecológicos dentro de suas instalações. Além de estimular a qualidade de alimentação de seus servidores insere no dia-a-dia a reflexão e conscientização sobre a prática de um modo de vida mais saudável.

Os servidores técnicos entrevistados demonstraram satisfação com a possibilidade de adquirir produtos agroecológicos prezando a qualidade da alimentação, detalhando inclusive o interesse por produtos que ainda não fazem parte do rol dos que já são ofertados. Apesar de terem apontado a necessidade de que se aumente a variedade, demostraram interesse em manter vínculo com produtos de origem agroecológica.

\section{Referências}

BRASIL. Lei no 11.892, de 29 de dezembro de 2008. Institui a Rede Federal de Educação Profissional, Científica e Tecnológica, cria os Institutos Federais de Educação, Ciência e Tecnologia, e dá outras providências. Disponível em: <http://www.planalto.gov.br/ccivil_03/_ato2007-2010/2008/lei//11892.htm> Acesso em: 28 de mai. de 2018.

CANUTO, J. C. Agroecologia: princípios e estratégias para o desenho de agroecossistemas sustentáveis. Redes. Santa Cruz do Sul: Universidade de Santa Cruz do Sul, v. 22, n. 2, Mai./Ago. 2017.

CAPORAL, F. R.; COSTABEBER, J. A. Agroecologia: alguns conceitos e princípios. 24 p. Brasília: MDA/SAF/DATER-IICA, 2004.

ParaOnde!?, Porto Alegre, v.13, n.2, p.16-27, 2020.http://seer.ufrgs.br/paraonde Edição Especial - VII Seminário Internacional de Estudos Fronteriços 
COSTA, E. A. et al. Perfil dos consumidores da feira de produtos de transição agroecológica na UFMS, Corumbá-MS, Brasil. Cadernos de Agroecologia v. 11, n. 2, p. 1-11, 2016.

CRUVINEL, I. B. et al. Fatores determinantes da tomada de decisão para o consumo de produtos orgânicos em uma feira livre. Revista Brasileira de Agropecuária Sustentável (RBAS), v.7, n.2, p.37-45, Jun. 2017.

DANTAS, S. R. C. et al. Avaliação do conhecimento e aceitabilidade dos produtos orgânicos oferecidos na feira agroecológica de Bananeiras-PB. Cadernos de Agroecologia, v. 6, n. 2, p. 1-5, Dez. 2011.

EDUARDO, M. F. Agroecologia e o processo de ativação de territorialidades camponesas. Revista Nera, ano 19, n. 31, p. 143-165, Mai./Ago., 2016.

ESPÍRITO SANTO, A. L., COSTA, E. A., BENEDETTI, A. G. Tramas territoriais na comercialização de produtos agrícolas em territórios fronteiriços. Mundo Agrário, v. 19, n. 42, e097. Dez. 2018.

GONÇALVES, K. S. et al. Agricultura Orgânica: Percepção de consumidores sobre a feira do Parque Água Branca, cidade de São Paulo-SP. 2016. XIII CONGRESSO NACIONAL DE MEIO AMBIENTE DE POÇOS DE CALDAS, 13. Anais... Poços de Caldas, MG, 2016. Disponível em: $<$ https://scholar.google.com.br/scholar?start=20\&q=perfil+de+consumidores+de +feira+agroecol\%C3\%B3gica\&hl=pt-BR\&as_sdt=0,5> Acesso em: 20 de ago. de 2019

GRIMNSON, A. Pensar fronteras desde las fronteras. Nueva Sociedad, Universidad de Buenos Aires, N. 170, Nov./Dec., 2000.

IFMS. Institucional. Disponível em: <http://www.ifms.edu.br/> Acesso em: 28 de mai. de 2018.

LOVATTO, P. et al. Caracterização do consumo em uma feira livre de base ecológica do Município de Pelotas, RS, Brasil. Rev. Bras. De Agroecologia, v. 4, n. 2, p. 3277-3281, Nov. 2009.

MACHADO, L. O. Limites, fronteiras e redes. In: STROHAECKER, T.M. et al. (Org.). Fronteiras e espaço global. Porto Alegre: AGB-Porto Alegre, 1998. p. 41-49.

NASCIMENTO, S. G. S. et al. Produção agroecológica e Segurança Alimentar e Nutricional (Brasil). Revista de Ciências Agrárias, v. 42, n. 1, p. 294-304, 2019.

NOGUEIRA, R. J. B. Fronteira: Espaço de Referência Identitária? Ateliê Geográfico Goiânia, v. 1, n. 2, p. 27-41, Dez. 2007.

RODRIGUES, A. L. Fronteira e território: considerações conceituais para a compreensão da dinâmica do espaço geográfico. Revista Produção Acadêmica - Núcleo de Estudos Urbanos Regionais e Agrários/NURBA, n. 2, p. 139-157, Dez. 2015.

SANTOS, C. F. et al. A agroecologia como perspectiva de sustentabilidade na agricultura familiar. Ambient. soc., São Paulo, v.17, n. 2, p. 33-52, Jun. 2014.

ParaOnde!?, Porto Alegre, v.13, n.2, p.16-27, 2020.http://seer.ufrgs.br/paraonde Edição Especial - VII Seminário Internacional de Estudos Fronteriços 
SEVILLA-GUZMÁN, E. Agroecología y agricultura ecológica: hacia una "re" construcción de la soberanía alimentaria. Agroecología, n.1, p. 7-18, 2006.

STEIMAN, R.; MACHADO, L. O. Limites e Fronteiras internacionais: uma discussão histórico-geográfica. Rio de Janeiro: Grupo Retis, 2002. Disponível em: http://www.igeo.ufrj.br/fronteiras. Acesso em: 31 de jul. 2019.

STOPPELLI, I. M. B. S.; MAGALHAES, C. P. Saúde e segurança alimentar: a questão dos agrotóxicos. Ciênc. saúde coletiva, Rio de Janeiro, v. 10, supl. p. 91-100, Dec. 2005. 